\title{
Mobile health clinics in the United States
}

\author{
Nelson C. Malone ${ }^{1}$, Mollie M. Williams ${ }^{2,3^{*}}$ (D), Mary C. Smith Fawzi ${ }^{2}$, Jennifer Bennet ${ }^{3}$, Caterina Hill ${ }^{2}$,
}

Jeffrey N. Katz ${ }^{1}$ and Nancy E. Oriol ${ }^{1,2,4}$

\begin{abstract}
Background: Mobile health clinics serve an important role in the health care system, providing care to some of the most vulnerable populations. Mobile Health Map is the only comprehensive database of mobile clinics in the United States. Members of this collaborative research network and learning community supply information about their location, services, target populations, and costs. They also have access to tools to measure, improve, and communicate their impact.

Methods: We analyzed data from 811 clinics that participated in Mobile Health Map between 2007 and 2017 to describe the demographics of the clients these clinics serve, the services they provide, and mobile clinics' affiliated institutions and funding sources.
\end{abstract}

Results: Mobile clinics provide a median number of 3491 visits annually. More than half of their clients are women (55\%) and racial/ethnic minorities (59\%). Of the 146 clinics that reported insurance data, $41 \%$ of clients were uninsured while $44 \%$ had some form of public insurance. The most common service models were primary care (41\%) and prevention (47\%). With regards to organizational affiliations, they vary from independent (33\%) to university affiliated (24\%), while some (29\%) are part of a hospital or health care system. Most mobile clinics receive some financial support from philanthropy (52\%), while slightly less than half (45\%) receive federal funds.

Conclusion: Mobile health care delivery is an innovative model of health services delivery that provides a wide variety of services to vulnerable populations. The clinics vary in service mix, patient demographics, and relationships with the fixed health system. Although access to care has increased in recent years through the Affordable Care Act, barriers continue to persist, particularly among populations living in resource-limited areas. Mobile clinics can improve access by serving as a vital link between the community and clinical facilities. Additional work is needed to advance availability of this important resource.

Keywords: Mobile clinics, Mobile health unit, Health disparities, Social determinants of health, Population health, Health care access

\section{Background}

The manner in which people receive health care in the United States has changed substantially over the last decade $[1,2]$. As the health care system continues to evolve, it is important to understand the role of mobile health providers. The estimated 2000 mobile clinics that are an integral part of the health care system help ensure access to care for millions and advance health equity [3]. A mobile clinic is a customized motor vehicle that travels to communities to provide health care. They

\footnotetext{
* Correspondence: mollie_williams@hms.harvard.edu

${ }^{2}$ Department of Global Health and Social Medicine, Harvard Medical School, Boston, USA

${ }^{3}$ The Family Van, Boston, USA

Full list of author information is available at the end of the article
}

deliver a wide variety of health services and may be staffed by a combination of physicians, nurses, community health workers, and other health professionals. While health care reform has expanded insurance coverage, many barriers to regular health care remain, especially for vulnerable populations [4-6]. Mobile health units help underserved communities overcome common barriers to accessing health care including time, geography, and trust, and have demonstrated improvements in health outcomes and reductions in costs [7-12].

Mobile Health Map, a program of Harvard Medical School, is the only comprehensive database of mobile clinics in the United States [13]. As members of this collaborative research network and learning community,

(c) The Author(s). 2020 Open Access This article is distributed under the terms of the Creative Commons Attribution 4.0 International License (http://creativecommons.org/licenses/by/4.0/), which permits unrestricted use, distribution, and 
mobile clinics not only supply information about their location, services, target populations, and costs, they also have access to free tools to measure, improve, and communicate their impact.

Using the data supplied by its members, this study describes the mobile health sector including the demographics of clients, services provided, clinics' geographic distribution, and clinics' affiliations and funding sources. Preliminary results reported in 2014 for data from 2007 to 2013 included data from 644 clinics [14]. This updated analysis includes data from 2007 to 2017, reflecting updated information from the preliminary report and new additions to the network since 2014, bringing the total to 811 clinics in the network.

\section{Methods}

The aim of this study is to describe the mobile health sector in the United States, including the patients, services, organizational structures, and funding sources. Mobile Health Map was created in 2007 as a partnership between the Mobile Healthcare Association (formerly Mobile Health Clinics Association), Harvard T.H. Chan School of Public Health, and The Family Van, a mobile clinic affiliated with Harvard Medical School. Initial funding was provided by Ronald McDonald House Charities, Harvard University Interfaculty Provost Grant, Boeing Company, the U.S. Department of Health and Human Services, and the Office of Minority Health. The U.S. Human Resources and Services Administration and the Institute for Healthcare Improvement supported the dissemination of the collaboration's work.

Clinics are invited to join the research network through a variety of recruitment techniques including presentations and exhibits at conferences; emails to the Mobile Healthcare Association members listserv; webinars and conferences sponsored by Institute for Healthcare Improvement, including the 100 Million Healthier Lives program and a U.S. Human Resources and Services Administration webinar series for grantees and grantors; and direct solicitation through online searches. Mobile Health Map consistently ranks among the top results for web searches about mobile health care resulting in many new additions to the network.

Of the estimated 2000 clinics around the country, a total of 811 had joined the network as of April 24, 2017, including 167 new clinics since 2014. Mobile clinics voluntarily submit data to Mobile Health Map's website using a series of online forms [13] and provide information about their organization, operations, services, and clients (Fig. 1). Clinics are asked to report on all indicators to the best of their knowledge as frequently as possible on an annual basis. To ensure the accuracy and consistency of the information provided, the Executive Director of Mobile Health Map and volunteers under her supervision had phone conversations with approximately $10 \%$ of clinics.

The database includes information on clinic office locations (city, state, country, and zip code). Clinics designate their target populations (employees, LGBTQ, public housing, schools, minorities, migrants, veterans, rural, homeless, low income, uninsured, and other populations). Clinics indicate the percentage of clients falling in various categories of age $(0-17,18-44,45-64$, and $65+$ ), gender, and insurance status (Medicaid/Children's Health Insurance Program, Medicare, private, and uninsured). They provide data on the types of care offered (prevention, dental, primary, mammography, maternal and infant health, pediatric, asthma, mental health, disaster relief, and other). The cost of operations, affiliations (independent/for profit, no parent organization, faith-based, insurer, health center, independent/nonprofit, university-affiliated, hospital, and other), and funding sources (from parent organizations, states, patients self-pay, public insurance, private insurance, federal, philanthropy, and other sources) of clinics are also provided.

The data presented represents the data collected over the entire 10-year period (2007-2017), with only the most recently updated data presented for each clinic if they reported during multiple years. All data are aggregated across the mobile clinic's population and do not include individual patient information. Results were compared to a preliminary analysis from 2014. If a clinic reported updated information since 2014, the updated information was used in our analysis. However, if a clinic has not reported since that time period, the insurance status of clients, for example, when they did report, was still used in our analysis.

\section{Analysis}

Clinic services, cost, and client demographic data were exported from Mobile Health Map website into Microsoft Excel. Aggregate client demographic information from the online impact and quality tools were uploaded to Qualtrics [15] and subsequently exported into Microsoft Excel. The estimated proportions across all clinics were derived from an unweighted mean of the estimate measurements provided by each individual clinic. For example, if clinic A reported that they served an estimated 50\% Asian clients and clinic B estimated an average of $30 \%$ Asian clients, the reported average per clinic would be $40 \%$ Asian clients. This approach was used because the goal of the analysis was to provide averages across clinics with the clinic being the unit of observation, rather than summarizing data at the individual level. While the use of a weighted average was considered to give greater weight to clinics with higher volume, this type of analysis was not possible because only 168 


\begin{tabular}{|c|c|}
\hline \multicolumn{2}{|l|}{ General service category } \\
\hline $\begin{array}{l}\neg \text { Asthma } \\
\neg \text { Dental } \\
\square \text { Disaster Relief } \\
\neg \text { Mammography } \\
\neg \text { Maternal and Infant Health } \\
\square \text { Mental Health }\end{array}$ & $\begin{array}{l}\text { Other Specialties } \\
\text { Pediatrics } \\
\text { Preventative } \\
\text { Primary Care } \\
\text { Vision }\end{array}$ \\
\hline \multicolumn{2}{|l|}{ Target Population } \\
\hline $\begin{array}{l}\text { Employee Wellness } \\
\text { Low Income } \\
\text { Homeless } \\
\text { LGBTQ } \\
\text { Migrants } \\
\text { Minorities }\end{array}$ & $\begin{array}{l}\text { Public Housing } \\
\text { Rural } \\
\text { Schools } \\
\text { Uninsured } \\
\text { Veterans } \\
\text { Other Populations }\end{array}$ \\
\hline \multicolumn{2}{|l|}{ Affiliation / Parent Organization } \\
\hline $\begin{array}{l}\text { Health Center } \\
\text { Hospital System } \\
\text { Indendent for Profit Company } \\
\text { Independent Non-Profit }\end{array}$ & $\begin{array}{l}\text { Insurer } \\
\text { University-Affiliated Program } \\
\text { No Parent Organization } \\
\text { Other }\end{array}$ \\
\hline \multicolumn{2}{|l|}{ Source of Funding } \\
\hline $\begin{array}{l}\neg \text { Federal } \\
\text { State } \\
\square \text { Philanthropy } \\
\square \text { Insurance }\end{array}$ & $\begin{array}{l}\text { Parent Organization } \\
\text { Patients Self-Pay } \\
\text { Other }\end{array}$ \\
\hline
\end{tabular}

Fig. 1 Screenshot of portion of New Clinic Entry form

of the clinics provided total patient volume. The number of clinics reporting on each variable differed and is depicted in the text, figured, and tables.

\section{Results}

\section{Affiliations and funding sources}

Though 33\% of the 286 reporting clinics were independent programs, mobile clinics are often part of a larger organization. The most common of these affiliations were with hospital systems in $29 \%$ and universities in $24 \%$. Nineteen percent (19\%) reported to be affiliated with health centers, $17 \%$ with insurance companies, and $12 \%$ with faith-based organizations (Fig. 2).

Of the 173 mobile clinics reporting on total annual cost, the average cost per mobile clinic operation was $\$ 632,369$. Of the 58 clinics designating themselves as a prevention clinic (excluding primary care), the average cost was $\$ 319,868$. Of the 58 primary care clinics reporting cost, the average was $\$ 981,092$. The average cost of the 37 dental clinics reporting was $\$ 1,169,559$.

To cover these costs, mobile health clinics depend heavily on philanthropy and government funding. Of the 281 clinics reporting on their sources, 52\% reported philanthropic support and $45 \%$ reported federal funding (Fig. 3). Health insurance companies also provide much of the funding: $38 \%$ reported revenue from public insurance providers and $37 \%$ from private insurance providers. Thirty-two percent of clinics reported client payments as a source of revenue.

\section{Client demographics}

A variable number of clinics reported on each data element. Of the 253 mobile clinics that reported information on the number of visits, the median number of annual visits was 3491 with an interquartile range (IQR) of 1828 to 6050 . One hundred sixty-six clinics also reported the number of new visitors annually, of which the median was 1200 new visits with an IQR of 574 to 


\section{Clinic Affiliations}

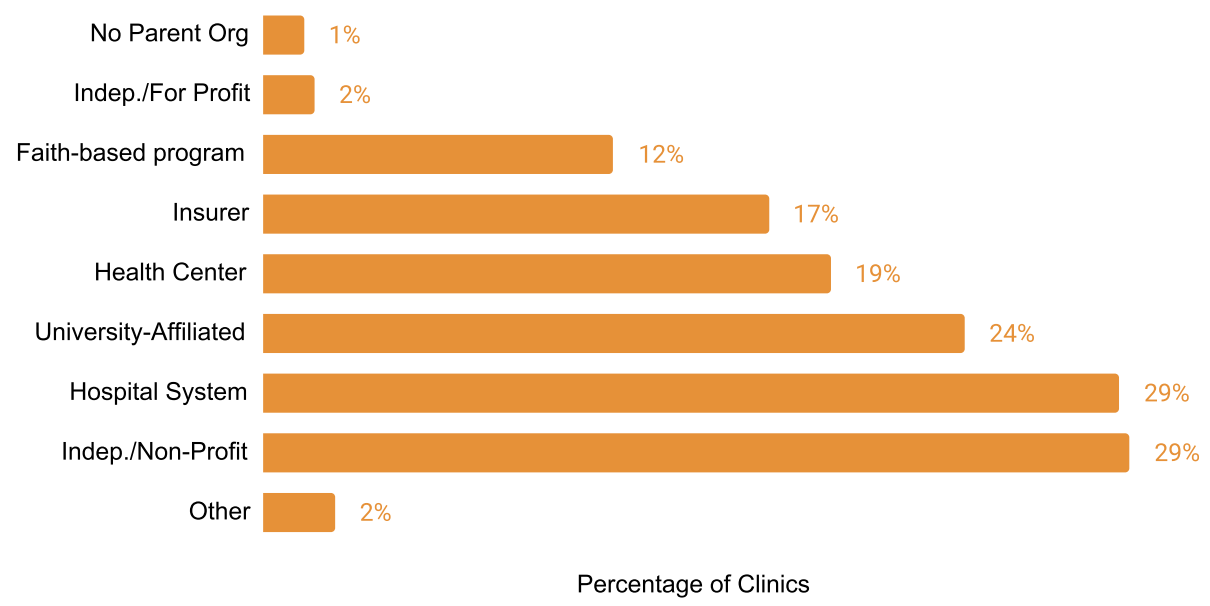

Fig. 2 Mobile Health Clinics Affiliations. 286 clinics report on the affiliations or parent organizations. *Clinics may designate multiple affiliations

2123.166 clinics also reported the average number of new visitors annually, of which the average was 2713 . One hundred ninty-two clinics reported gender distribution. Female clients make up a slight majority with each mobile clinic serving an average of 55\% female clients and $44 \%$ male clients. A category for transgender people was recently added.

Of the 183 clinics that reported on age, the average percentage of clients between 0 and 17 years of age was $41 \%$, and the average percentage falling between 18 and 44 years was $20 \%$ per clinic (Table 1 ). The average percentage of clients $45-64$ years of age was $31 \%$ per clinic, and the lowest utilization is found in the age group $65+$ with an average $11 \%$ per clinic.

One hundred eighty-six clinics provided data on the race/ethnicity of clients. The average percentage of white clients was $42 \%$, Black/African-American clients was $35 \%$, and Hispanic clinics was $27 \%$ (Table 1).
The average percentage of Asians, Native American, multiracial, and those clients designating their ethnicity as "other" were less than $5 \%$.

Many mobile clinics aim to reach populations with limited access to care. To understand which client populations the clinics were designed to serve, clinics are asked to report the group or groups they target. Of the 291 clinics reporting, 56\% targeted the uninsured, 55\% low-income groups, 38\% homeless persons, and $36 \%$ rural communities (Fig. 4).

Of the 146 clinics that provided information on insurance status of clients, the average percentage of uninsured clients was approximately $41 \%$. The average percent of clients covered by Medicaid/CHIP was $30 \%$ per clinic and by Medicare was $15 \%$ per clinic. The average reported percentage of clients with private insurance was $25 \%$ per clinic, some of whom also have coverage with public insurance.

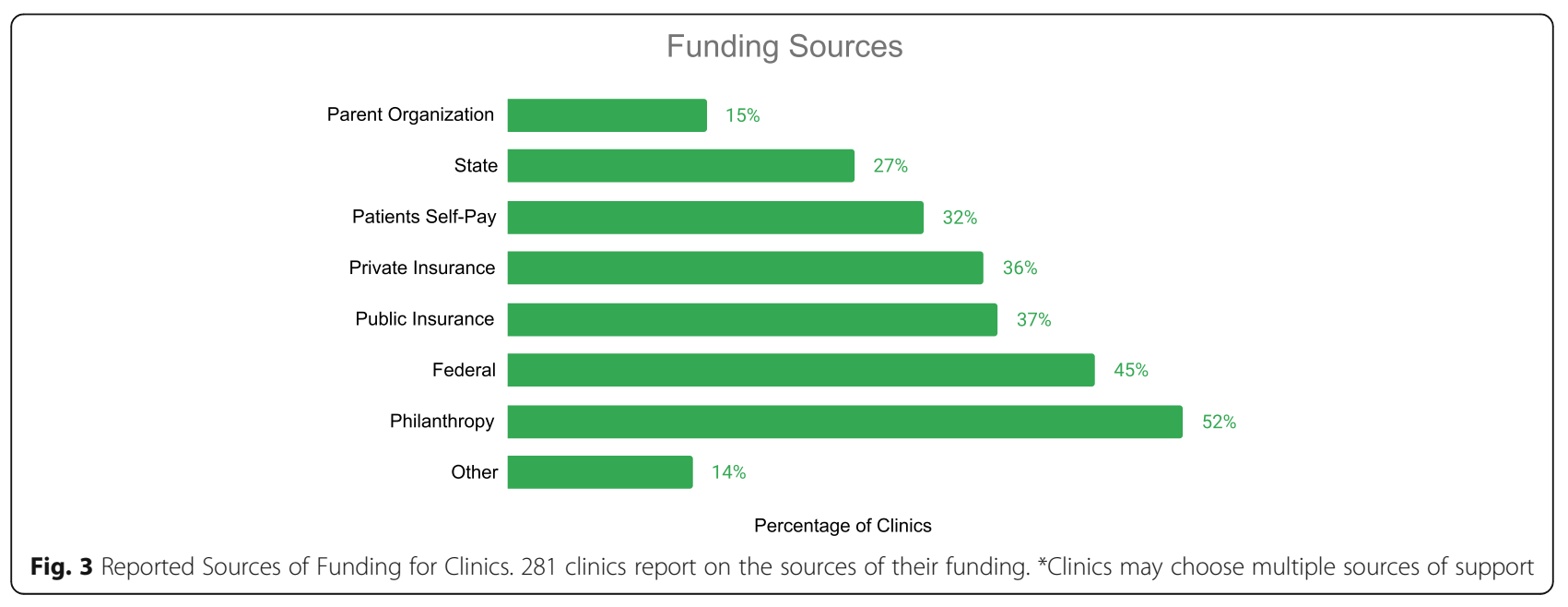




\section{Target Populations}

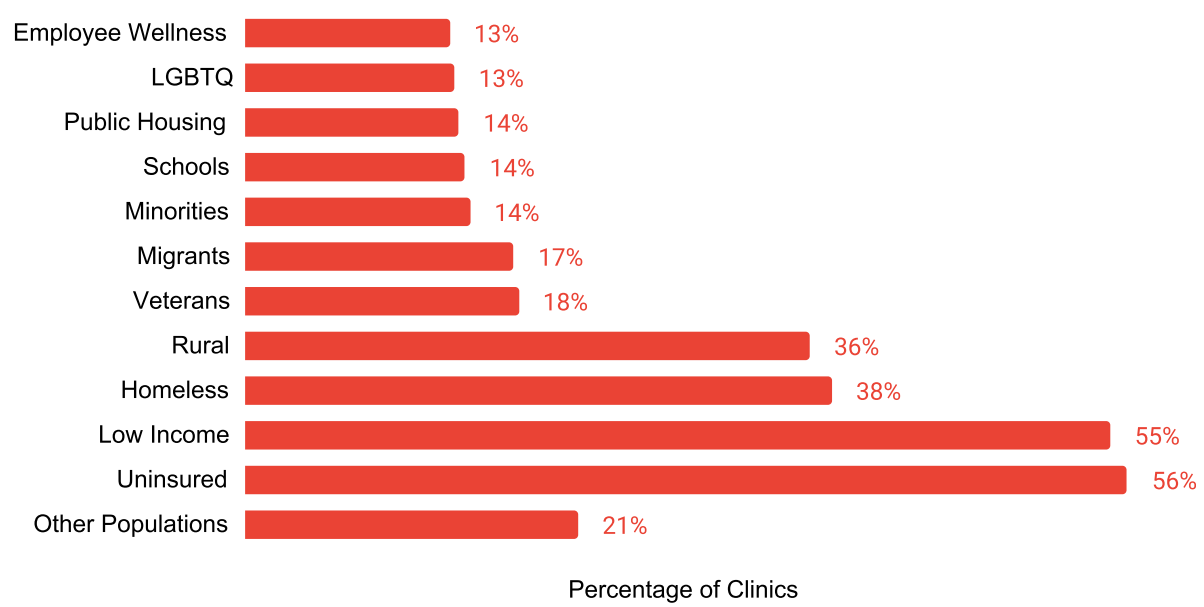

Fig. 4 Two hundred ninety-one mobile clinics report on the specific groups they target. *Clinics may select more than one option

\section{Services offered}

Mobile clinics have the option to report on the type of services they offer. Of the 724 clinics that provided information on service type, $47 \%$ reported that they provide prevention services exclusively, $41 \%$ reported to be primary care focused, and $28 \%$ reported to provide dental care (Fig. 5). Mammography, pediatric, mental health, asthma, maternal and infant health, disaster relief, vision, and other specialty services are also provided by mobile clinics.

Of the 67 clinics reporting on specific services/screenings provided, $31 \%$ provided screening for hypertension, $31 \%$ provided diabetes screenings and treatment (or referral to treatment), $28 \%$ provided diet counseling, and $27 \%$ provided cholesterol screenings. The mobile clinics also offer screening for colorectal (13\%), cervical (13\%) and breast cancer (19\%) and osteoporosis (9\%). There are also services for hearing (6\%), vision (13\%), depression (25\%), and obesity (25\%). Clinics describe discussion of daily aspirin use (13\%), calcium supplementation (12\%), and folic acid use for women of childbearing age (13\%). Smoking cessation advice (25\%) and alcohol screening and brief counseling for alcohol use (25\%) are also provided on some clinics.

\section{Geographic distribution}

Mobile clinics operate in all 50 states, the District of Columbia, and Puerto Rico (Table 2). Many are located in areas of high population density in major cities around the country such as Atlanta, Boston, Chicago, Dallas, Denver, Houston, Los Angeles, New York, Orlando, Phoenix, San Francisco, San Jose, Seattle, and St. Louis (Fig. 6). There are also clinics located in less populated areas.

Table 1 Age and Race/Ethnicity Distribution of Mobile Clinic Clients. 183 and 186 mobile clinics' estimates of the percentage of clients visiting their clinics annually stratified by age and race/ethnicity, respectively

\begin{tabular}{lc}
\hline Age & Average Percentage of Clients \\
$0-17$ years old & $40.9 \%$ \\
$18-44$ years old & $20.0 \%$ \\
$45-64$ years old & $30.9 \%$ \\
$65+$ years old & $10.5 \%$ \\
Race/Ethnicity & Average Percentage of Clients \\
White (not Hispanic / Latino) & $41.5 \%$ \\
Black / African American & $35.3 \%$ \\
Hispanic / Latino & $26.6 \%$ \\
Mixed / Other & $4.1 \%$ \\
Asian & $2.8 \%$ \\
American Indians and Alaska Natives & $1.8 \%$ \\
Native Hawaiians and other Pacific Islanders & $1.0 \%$ \\
\hline
\end{tabular}




\section{Service Types}

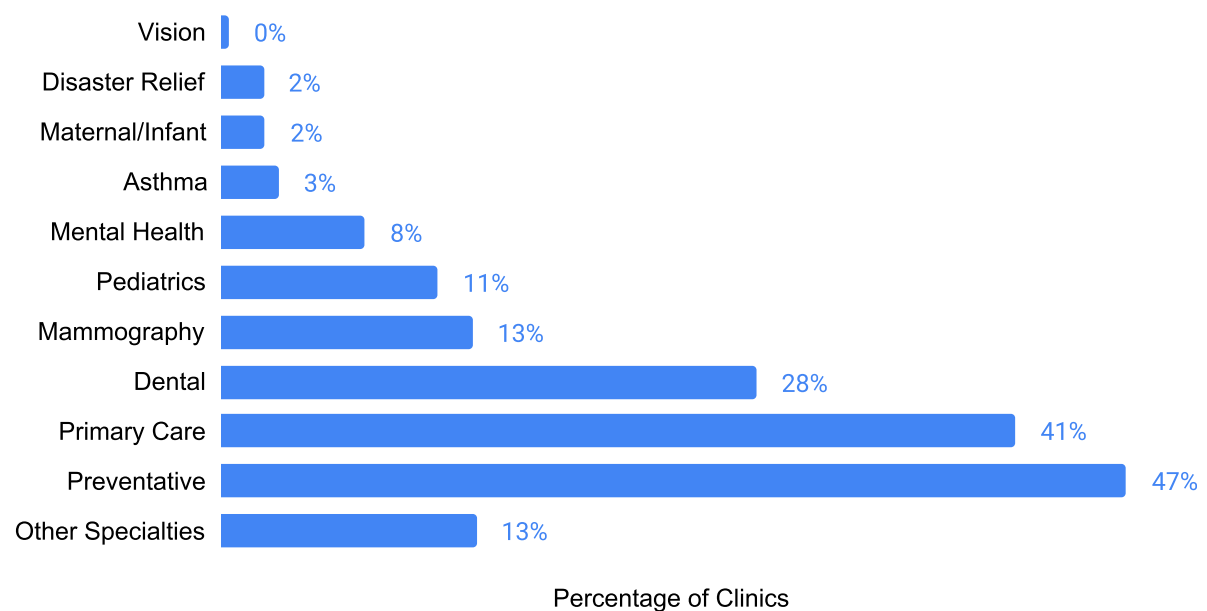

Fig. 5 Services Reported by Mobile Clinics. 724 clinics reported on the serve type of their clinic. The "other specialty" category includes vision, asthma, maternal and infant health, disaster, homelessness, and other services

\section{Discussion}

Mobile health clinics deliver care to some of the country's most vulnerable populations, including people of color, people experiencing poverty and/or homelessness, the uninsured, rural communities, veterans, and immigrants. They are located across the United States and operate with the financial support of health care systems, universities, philanthropy, and government agencies.

The people and organizations that operate mobile clinics are often motivated by a commitment to underserved communities and use the mobile clinic as a vehicle to deliver care in ways that differ from traditional medical settings. For example, Bouchelle and colleagues reported that The Family Van, a mobile clinic in Boston, creates a culture of respect and inclusivity [16]. In many instances, mobile clinics serve as a bridge between communities and the health care system. As health care leaders and policymakers increasingly recognize the importance of social determinants of health and community-clinical linkages, mobile clinics are well-positioned to further these goals.

Table 2 Number of Mobile Health Clinics by State. This table shows the number of mobile health clinics represented by each state on the Mobile Health Map

\begin{tabular}{|c|c|c|c|c|c|c|c|}
\hline Northeast & & Midwest & & South & & West & \\
\hline Connecticut & 6 & Illinois & 25 & Florida & 36 & Arizona & 21 \\
\hline Maine & 7 & Indiana & 5 & Georgia & 16 & Colorado & 12 \\
\hline Massachusetts & 29 & Michigan & 13 & Maryland & 14 & Idaho & 4 \\
\hline New Hampshire & 4 & Ohio & 13 & North Carolina & 41 & Montana & 4 \\
\hline Rhode Island & 3 & Wisconsin & 8 & South Carolina & 12 & Nevada & 1 \\
\hline Vermont & 1 & lowa & 2 & Virginia & 15 & New Mexico & 7 \\
\hline Delaware & 3 & Kansas & 13 & District of Columbia & 3 & Utah & 2 \\
\hline New Jersey & 9 & Minnesota & 9 & West Virginia & 4 & Wyoming & 2 \\
\hline New York & 61 & Missouri & 15 & Alabama & 7 & Alaska & 2 \\
\hline \multirow[t]{6}{*}{ Pennsylvania } & 16 & Nebraska & 4 & Kentucky & 11 & California & 120 \\
\hline & & North Dakota & 3 & Mississippi & 7 & Hawaii & 13 \\
\hline & & South Dakota & 3 & Tennessee & 15 & Oregon & 13 \\
\hline & & & & Arkansas & 5 & Washington & 20 \\
\hline & & & & Louisiana & 23 & & \\
\hline & & & & Oklahoma & 5 & & \\
\hline *Puerto Rico & 1 & & & Texas & 61 & & \\
\hline
\end{tabular}




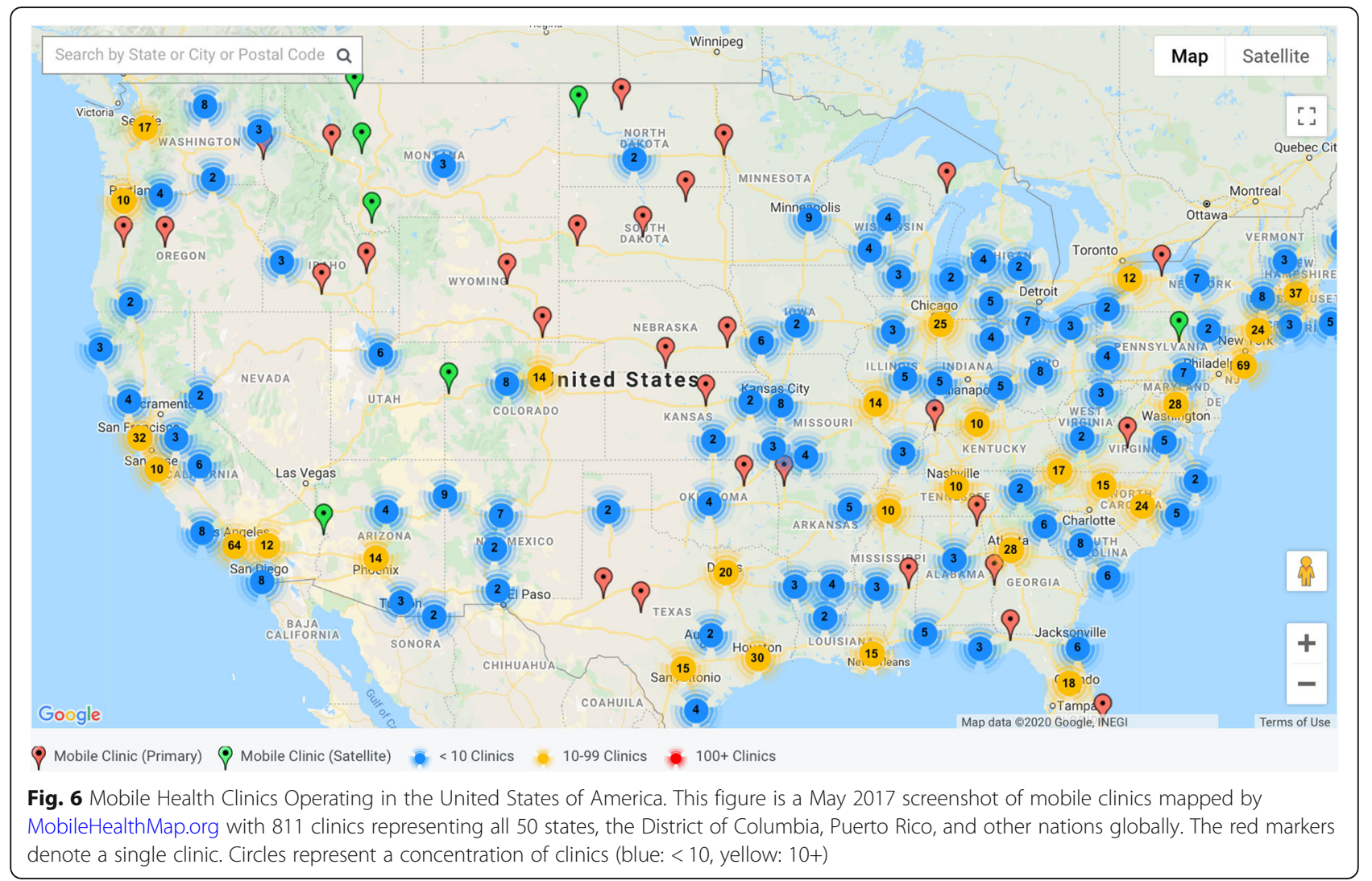

Using the median number of annual visits (3491) and the estimated 1500 to 2000 mobile clinics nationwide, we estimate 5.2 to 7.0 million visits to mobile health clinics each year. Assuming the lower estimate of 5.2 million visits, there are an estimated 2.1 million visits by uninsured persons, 2.3 million visits by publicly insured persons, and 2.1 million visits by children to mobile health clinics.

Mobile clinics saw a greater percentage of people of color than then the general U.S. population. For example, in the 2010 U.S. Census $13.4 \%$ of respondents reported a race of Black or African American. In contrast, the average percentage of Black or African American clients in this sample is $35 \%$. In the same census, $18.3 \%$ of residents identified as Latino or Hispanic. In this group of mobile clinics, the average percentage of Latino or Hispanic clients was 26.6\% [17].

Comparing the results of this analysis to those of the initial data collection published in 2014, it is notable that the percentage of people attending mobile clinics that were uninsured dropped from 57 to $40 \%$. This drop may be due to the implementation of the Affordable Care Act. It suggests that many mobile clinics that previously served uninsured patients adapted to the new health care environment and are able to bill insurance for visits that were previously supported through other means, like philanthropy.
Mobile health clinics straddle the community and health care system. They often address important social determinants of health including food and housing insecurity, education, and job opportunities. By collaborating with local agencies such as churches, community health centers, and other hospitals and clinics, mobile clinics connect community members with both medical and social services.

Though mobile clinics operate all over the country, they are commonly located in densely populated cities. There is a lack of clinics in the rural parts of every state and many parts of the Midwest, and as a result, populations that may continue to be void of adequate access to health care and areas where mobile clinics can have an impact.

Mobile Health Map is a powerful tool for the mobile health sector to understand itself and demonstrate its role in the greater health care system. This information can help policy makers, payers and providers understand the services they provide and the vulnerable populations they serve. Understanding this will help clinics advocate for their role as a critical part of the health care safetynet and experts in community-clinic linkage.

Mobile Health Map is a pioneer in the mobile health sector and is the source of much of the existing scholarship in the area $[3,14,18]$. The database allows researchers and practitioners to monitor and evaluate 
the sector and its impact. Further research is needed to understand the changing role of mobile health care in value-based payment models, as well as how mobile health providers integrate behavioral health services.

\section{Limitations}

Of the estimated 2000 mobile clinics around the nation, 811 were registered with the Mobile Health Map as of April 24, 2017. These programs are self-selected and self-reporting. Because there is no similar database of mobile clinics, it is not possible to evaluate the representativeness of our sample. While some clinics outside the U.S. participate in Mobile Health Map, they are not the primary audience and as such, this analysis is also limited to clinics in the U.S. However, for a health care sector previously uncharted, this sample gives us a broad picture of the state of mobile health in the U.S.

Many clinics provide the address of the location where they are headquartered rather than the individual communities they serve. As a result, the breadth of communities served, and thus the true scope of the sector, is likely underestimated by this study. All data provided about costs are self-reported and clinics may differ by the types of costs (e.g. operating, capital) they include.

Given the provision of care for primary and secondary prevention available at mobile clinics, it is highly likely that health outcomes can improve with concomitant cost savings. Therefore, future studies should consider these outcomes. Despite these limitations, the results of the study provide insight on the innovative ways mobile clinics expand the boundaries of the health care system and improve health equity, especially among our most vulnerable populations.

\section{Conclusion}

With an increasing emphasis on population health and meeting people where they work, live, and play, understanding why and how these systems operate can inform effective community-clinical linkages. While mobile clinics exist across the country, many underserved rural areas and under-resourced urban areas continue to suffer from health disparities that could be addressed by expanding the network of mobile clinics.

Mobile clinics reduce barriers to health care including transportation, time, system complexity, and trust. They are an integral part of the health care system and are supported by government agencies, insurance companies, and philanthropy. To advance health equity and reach the most vulnerable and disenfranchised populations, we need to increase investment in mobile clinics and other innovative ideas that promote preventive services and expand the boundaries of the traditional health care system.

\section{Abbreviations}

CHIP: Children's health insurance program; LGBTQ: lesbian, gay, bisexual, transgender, transsexual, queer

\section{Acknowledgements}

The authors would like to thank Erik Erlingsson, MD, MS, MPH, for assisting with quality assurance and manuscript edits. Thank you also to Harvard Medical School, The Family Van, Mobile Health Map for in-kind support. We would also like to acknowledge the efforts of all of the mobile clinics that contributed data on the Mobile Health Map website.

\section{Authors' contributions}

N C. M analyzed and interpreted the datasets on the mobile clinics and was the main author of the manuscript. M M. W provided expertise related to the national mobile health care sector, made substantial contributions to interpretation of the data, edited and revised the manuscript critically for important intellectual content, and incorporated revisions and obtained final approval from all other authors. M C. S F was involved with mentoring the first author, guiding the analysis, drafting brief sections, and revising the overall manuscript. C H and J B played critical roles in the acquisition, analysis, and interpretation of data and provided expertise related to the national mobile healthcare service sector. J N. K provided significant help in reviewing the literature and revising the manuscript critically for important intellectual content. N O is the founder of Mobile Health Map and contributed substantially to the design of the study. All authors read, made substantive revisions, and approved the final manuscript.

\section{Authors' information}

Nelson C. Malone is a current medical student at Harvard Medical School who is also pursuing an MPH at Johns Hopkins Bloomberg School of Public Health. Mary C. Smith Fawzi is an Assistant Professor of Global Health and Social Medicine at Harvard Medical School. Jennifer Bennet is the former Executive Director of The Family Van and Mobile Health Map. Caterina Hill is a lecturer on Global Health and Social Medicine at HMS. Jeffrey N. Katz is a Professor of Medicine and Orthopaedic Surgery at HMS and in the Departments of Epidemiology and Environmental Health at Harvard T.H. Chan School of Public Health. Nancy E. Oriol is the Faculty Associate Dean for Community Engagement in Medical Education at HMS and founder of The Family Van and Mobile Health Map. Mollie M. Williams is the current director of The Family Van and Mobiile Heealth Map and a Lecturer at Harvard Medical School, Department of Global Health and Social Medicine.

\section{Funding}

Mobile Health Map funding: Harvard University Provost, Ronald McDonald House Charity, Boeing Corporation, Office of Minority Health, US Health and Human Services and Aetna Foundation.

\section{Availability of data and materials}

The datasets generated and/or analyzed during the current study are not publicly available due to clinic privacy, but aggregated data about members is available from the corresponding author upon reasonable request.

\section{Ethics approval and consent to participate}

No ethics approval was required. Members of Mobile Health Map consent to sharing their information in aggregate as part of the user registration process.

\section{Consent for publication}

This paper does not contain any individual person's data.

\section{Competing interests}

The author(s) declare(s) that they have no competing interests.

\section{Author details}

${ }^{1}$ Harvard Medical School, Boston, USA. ${ }^{2}$ Department of Global Health and Social Medicine, Harvard Medical School, Boston, USA. ${ }^{3}$ The Family Van, Boston, USA. ${ }^{4}$ Department of Anesthesia and Critical Care, Beth Israel Deaconess Medical Center, Boston, USA. 
Received: 27 August 2019 Accepted: 4 February 2020

Published online: 20 March 2020

\section{References}

1. Poon SJ, Schuur JD, Mehrotra A. Trends in visits to acute care venues for treatment of low-acuity conditions in the United States from 2008 to 2015. JAMA Intern Med. 2018;178(10):1342-9.

2. Barnett ML, Ray KN, Souza J, Mehrotra A. Trends in telemedicine use in a large commercially insured population, 2005-2017. JAMA. 2018;320(20): 2147-9.

3. Yu SWY, Hill C, Ricks ML, Bennet J, Oriol NE. The scope and impact of mobile health clinics in the United States: a literature review. Int J Equity Health. 2017;16:178. https://doi.org/10.1186/s12939-017-0671-2.

4. Sommers BD. Health care Reform's unfinished work - remaining barriers to coverage and access. N Engl J Med. 2015:373(25):2395-7.

5. Clark CR, Soukup J, Govindarajulu U, Riden HE, Tovar DA, Johnson PA. Lack of access due to costs remains a problem for some in Massachusetts despite the State's health reforms. Health Aff (Millwood). 2011;30(2):247-55.

6. Guruge S, Hunter J, Barker K, McNally MJ, Magalhães L. Immigrant women's experiences of receiving care in a mobile health clinic. J Adv Nurs. 2010; 66(2):350-9.

7. Oriol NE, Cote PJ, Vavasis AP, Bennet J, DeLorenzo D, Blanc P, et al. Calculating the return on investment of mobile healthcare. BMC Med. 2009; 7:27. https://doi.org/10.1186/1741-7015-7-27.

8. Malone S. Mobile clinics seen as way to cut U.S. health bill. Reuters [Internet]. 201011 [cited 2019 Mar 8]; Available from: https://www.reuters. com/article/us-usa-health-mobile-idUSTRE67A4C020100811. Accessed 8 Mar 2019.

9. Song Z, Hill C, Bennet J, Vavasis A, Oriol NE. Mobile clinic in Massachusetts associated with cost savings from lowering blood pressure and emergency department use. Health Aff (Millwood). 2013;32(1):36-44.

10. Brown-Connolly NE, Concha JB, English J. Mobile health is worth it! Economic benefit and impact on health of a population-based Mobile screening program in New Mexico. Telemed J E Health. 2014 Jan 1;20(1):18-23.

11. Drake BF, Abadin SS, Lyons S, Chang S-H, Steward LT, Kraenzle S, et al. Mammograms on-the-go--predictors of repeat visits to mobile mammography vans in St Louis, Missouri, USA: a case-control study. BM Open. 2015;5(3):e006960.

12. Taylor LA, Tan AX, Coyle CE, Ndumele C, Rogan E, Canavan M, et al. Leveraging the social determinants of health: what works? Yi H, editor. PLoS One. 2016;11(8):e0160217.

13. Mobile Health Map [Internet]. [cited 2019 Feb 22]. Available from: https:// www.mobilehealthmap.org. Accessed 22 Feb 2019.

14. Hill CF, Powers BW, Jain SH, Bennet J, Vavasis A, Oriol NE. Mobile health clinics in the era of reform. Am J Manag Care. 2014;20(3):261-4.

15. Qualtrics [Internet]. Provo, UT, USA; 2017. Available from: https://www qualtrics.com. Accessed 27 Apr 2017.

16. Bouchelle Z, Rawlins Y, Hill C, Bennet J, Perez LX, Oriol N. Preventative health, diversity, and inclusion: a qualitative study of client experience aboard a mobile health clinic in Boston, Massachusetts. Int J Equity Health. 2017;16(1):191. https://doi.org/10.1186/s12939-017-0688-6.

17. United States Census. [Internet] [cited 2019 Oct 28] Available from: https:// www.census.gov/quickfacts/fact/table/US/POP010210. Accessed 28 Oct 2019.

18. Aung KK, Hill C, Bennet J, Song Z, Oriol NE. The Emerging Business Models and Value Proposition of Mobile Health Clinics. Am J Accountable Care. 2015:3(4):36-40

\section{Publisher's Note}

Springer Nature remains neutral with regard to jurisdictional claims in published maps and institutional affiliations.

\section{Ready to submit your research? Choose BMC and benefit from:}

- fast, convenient online submission

- thorough peer review by experienced researchers in your field

- rapid publication on acceptance

- support for research data, including large and complex data types

- gold Open Access which fosters wider collaboration and increased citations

- maximum visibility for your research: over $100 \mathrm{M}$ website views per year

At $\mathrm{BMC}$, research is always in progress.

Learn more biomedcentral.com/submissions 